\title{
Dynamic Expression of the Basic Helix- Loop-Helix Transcription Factor NeuroD in the Rod and Cone Photoreceptor Lineages in the Retina of the Embryonic and Larval Zebrafish
}

\author{
MALGORZATA J. OCHOCINSKA ${ }^{1,2}$ AND PETER F. HITCHCOCK ${ }^{1,2 *}$ \\ ${ }^{1}$ Department of Ophthalmology and Visual Sciences, W.K. Kellogg Eye Center, Ann Arbor, \\ Michigan 48105 \\ ${ }^{2}$ The Neuroscience Graduate Program, University of Michigan, Ann Arbor, Michigan 48109
}

\begin{abstract}
NeuroD is a basic helix-loop-helix (bHLH) transcription factor critical for determining neuronal cell fate and regulating withdrawal from the cell cycle. We showed previously that, in goldfish, neuro $D$ is expressed in the rod photoreceptor lineage, and we inferred that neuroD is also expressed in a subset of amacrine cells and nascent cone photoreceptors. Here we extended that study by examining the temporal and spatial expression pattern of neuroD in the embryonic and larval zebrafish and by identifying the cell types that express this gene. NeuroD expression in the developing zebrafish retina is dynamic, spanning early retinogenesis and the maturation of cone photoreceptors. In early retinogenesis neuro $D$ expression expands from a small patch in the ventronasal retina, through the remaining retinal neuroepithelium. As retinogenesis progresses, neuroD expression becomes restricted to amacrine cells, immature cones, and cells of rod and cone lineages. This expression achieves an adult pattern by 96 hours postfertilization (hpf), whereupon the temporal pattern of neuroD expression in central retina is spatially recapitulated at the germinative margin. The cellular pattern of expression suggests that neuroD regulates aspects of rod and cone genesis, but through separate cellular lineages. Furthermore, neuroD is coexpressed with the cone-rodhomeobox transcription factor (Crx) in putative cone progenitors and nascent cone photoreceptors, suggesting that, in the zebrafish retina, as in other vertebrate retinas, similar genetic cascades regulate photoreceptor genesis and maturation. J. Comp. Neurol. 501:1-12, 2007. () 2007 Wiley-Liss, Inc.
\end{abstract}

Indexing terms: neurogenesis; development; gene expression; photoreceptors

NeuroD is a member of a family of basic helix-loop-helix transcription factors that acts as a molecular link connecting withdrawal from the cell cycle, cell fate determination, differentiation, and survival of postmitotic cells (Chae et al., 2004). These properties were first demonstrated in Xenopus embryos, where ectopic expression converts epithelial cells into neurons (Lee et al., 1995), and in vitro, where transfection of P19 cells induces cell cycle withdrawal and the expression of neuronal proteins (Farah et al., 2000; see also Cho et al., 2001). In the brain and nonnervous tissues, neuroD has specific functions based on the mitotic state of the cell. In mitotically active cells, neuroD regulates proliferation (Miyata et al., 1999; Nibu et al., 2001; Manglapus et al., 2004; Schonhoff et al., 2004;
Lawoko-Kerali et al., 2004) and exit from the cell cycle (Mutoh et al., 1998), and its absence results in prolifera-

Grant sponsor: National Institutes of Health; Grant number: T32 EY013934 (Vision Science Training Grant; to M.J.O.); RO1 EY07060 (to P.F.H.); Grant number: P30 EY07003 (Core Grant for Vision Research to the University of Michigan).

*Correspondence to: Peter F. Hitchcock, W.K. Kellogg Eye Center, The University of Michigan, 1000 Wall Street, Rm. 418, Ann Arbor, MI 48105. E-mail: peterh@umich.edu

Received 9 March 2006; Revised 19 June 2006; Accepted 28 July 2006 DOI 10.1002/cne.21150

Published online in Wiley InterScience (www.interscience.wiley. com). 
tion defects. In postmitotic cells, neuroD is required for survival, and its absence results in cell death during differentiation (Miyata et al., 1999; Schwab et al., 2000; Lee et al., 2000; Cai et al., 2000; Liu et al., 2000a,b; Kim et al., 2001; Nibu et al., 2001). NeuroD retains these functions in persistently mitotic tissues in adult animals (Naya et al., 1997; Mutoh et al., 1998; Kim et al., 2001; Bedard and Parent, 2004; Schonhoff et al., 2004). Whereas neuroD may play a variety of roles throughout development, it appears that its function can be divided into common categories that involve cell cycle regulation, cell fate specification, and cell survival. More importantly, neuroD may serve as the common link that connects all these processes. Determining the fundamental functions of neuroD will be an important step toward understanding the complex cellular mechanisms that regulate neurogenesis.

NeuroD may play similar, conserved roles in the developing retina, but the cellular details appear to be species specific. In the mouse retina, neuroD expressed in multipotent retinal progenitors regulates neuronal vs. glial cell fate and is determinative for amacrine cells (Acharya et al., 1997; Ahmad et al., 1998; Morrow et al., 1999; Moore et al., 2002; Inoue et al., 2002; Pennesi et al., 2003). Furthermore, neuroD-null mice show age-related degeneration of rod photoreceptors (Pennesi et al., 2003), indicating that, in mammals, neuroD regulates the survival of a subset of postmitotic retinal cells. In the chick, neuroD is also expressed in multipotent progenitors but is determinative for cone and rod photoreceptors only (Yan and Wang, 1998, 2000, 2004; see also Fischer et al., 2004). In adult goldfish, neuroD is not expressed in multipotent progenitors but is expressed in mitotic cells that give rise exclusively to rod photoreceptors. In addition, neuroD is transiently expressed in newly postmitotic cone photoreceptors (Hitchcock and Kakuk-Atkins, 2004).

The teleost retina is persistently neurogenic, and this process is made possible, in part, by the continued presence of stem cells. The circumferential germinal zone is the location of stem cells that give rise to all retinal cell types, with the exception of rod photoreceptors. In contrast, stem cells residing in the inner nuclear layer give rise exclusively to rod photoreceptors (Raymond and Rivlin, 1987; Otteson et al., 2001; Otteson and Hitchcock, 2003). Rod genesis in teleosts is an example of a lineage of cells generating a single cell type. Stem cells in the inner nuclear layer give rise to rod progenitors that traverse from the inner nuclear layer to the outer nuclear layer and become rod precursors, which in turn both divide and differentiate into rod photoreceptors. Recent findings revealed that both rod progenitors and rod precursors express neuroD, which suggests that, in teleosts, neuroD might play a specific role in generating this one cell type (Hitchcock and Kakuk-Atkins, 2004). This is further substantiated by the fact that neuroD is not expressed in multipotent progenitors (Hitchcock and Kakuk-Atkins, 2004). Thus, whereas in homeothermic vertebrates, such as the mouse and chick, neuroD in the retina appears to play a role in cell fate determination, in the adult teleost retina it appears to play a more restricted role in generating rod photoreceptors. Whether early photoreceptor genesis in teleosts fits the avian and mammalian models remains to be determined.

The zebrafish has recently become a prominent system in developmental biology, amenable to approaches that investigate gene regulation and function. Furthermore, zebrafish retinal development has been extensively studied, and neuroD is expressed in the retina (Korzh et al., 1998; Masai et al., 2000; Mueller and Wullimann, 2002). The function of neuroD in the teleost retina has not yet been experimentally investigated, and the spatial and temporal expression pattern of this gene during embryonic and larval development of the retina is not yet known. The aim of the current study is to characterize the cellular expression of neuroD in the embryonic and larval retina of the zebrafish and to establish the identity of the cells that express this gene. These data regarding the cellular expression can then be used to predict neuroD function, which can be tested by using reverse genetic approaches.

Our results show that neuroD is first expressed in ventronasal retina in a small cluster of proliferative cells. As neurogenesis and lamination proceed, neuroD expression becomes confined to four cell types in two nuclear layers: a small subset of differentiated amacrine cells in the inner nuclear layer, immature cone photoreceptors in the outer nuclear layer, cells of the rod lineage that span these layers, and dividing cells at the circumferential germinal zone that give rise to cone photoreceptors. NeuroD expression in separate cellular lineages that give rise to rods and cones suggests that, in teleosts, this gene regulates aspects of photoreceptor genesis. Transient expression of neuroD in newly postmitotic cones further suggests that this gene regulates aspects of cone maturation. In addition, neuroD and the cone-rod homeobox gene Crx are coexpressed in nascent cones and putative cone progenitors, suggesting that neuroD may interact with Crx within developing photoreceptors. The evidence presented here expands upon the current model of photoreceptor genesis in teleosts and begins to elucidate the genetic cascade leading to photoreceptor genesis in the zebrafish retina.

\section{MATERIALS AND METHODS}

Wild-type zebrafish were used to generate embryos. Breeders were maintained on a 14-hours-light/10-hoursdark daily cycle, and embryos were collected following light onset. Embryos were maintained in embryo rearing solution (ERS; Westerfield, 2000) for the first 12 hours and then placed in ERS containing $0.2 \mathrm{mM}$ 1-phenyl-2thiourea (PTU; Sigma, St. Louis, MO) to prevent melanin pigmentation. Embryos were raised at $28.5^{\circ} \mathrm{C}$, staged in hours postfertilization (hpf) according to Westerfield (2000), and analyzed between $25 \mathrm{hpf}$ and $96 \mathrm{hpf}$. Protocols for animal husbandry and death were approved by the University Committee for Use and Care of Animals (UCUCA) at the University of Michigan and conform to $\mathrm{NIH}$ guidelines.

\section{Histology}

Embryos were dechorionated with watchmakers' forceps, if necessary, and fixed in $4 \%(\mathrm{w} / \mathrm{v})$ paraformaldehyde for 1 hour at room temperature. Different protocols were followed for specimens processed as whole mounts or histological sections. For whole-mount in situ hybridization, fixation was followed by two 5-minute washes in $0.1 \mathrm{M}$ phosphate-buffered saline (PBS; pH 7.2) and two 5-minute washes in $100 \%$ methanol. The embryos were then placed in a $100 \%$ methanol solution and stored at $-20^{\circ} \mathrm{C}$ for at least 30 minutes before proceeding with the in situ hybridization protocol. For sectioned animals, fixation was followed by infiltration in $20 \%$ sucrose in PBS overnight. 
On the next day, animals were washed in 2:1 (20\% sucrose: OCT medium) for 30 minutes and frozen in TissueTek Optimal Cutting Temperature (O.C.T.) medium (Sakura Finetek U.S.A., Inc., Torrance, CA). Sections were cut on a cryostat in the frontal plane at $5 \mu \mathrm{m}$.

\section{In situ hybridization}

In situ hybridization of whole embryos was performed according to Westerfield (2000) in 1.5-ml Eppendorf tubes. Embryos stored in $100 \%$ methanol at $-20^{\circ} \mathrm{C}$ were returned to room temperature, rehydrated, fixed in $4 \%$ paraformaldehyde, permeabilized with $0.1 \mathrm{M}$ proteinase $\mathrm{K}$, fixed a second time in $4 \%$ paraformaldehyde, treated with acetic anhydride, washed in PBS with $1 \%$ Tween, and prehybridized in hybridization buffer for 1-2 hours. The prehybridization solution was removed, and $200 \mathrm{ng}$ of probe in $80 \mu \mathrm{l}$ of hybridization solution was pipetted onto embryos and hybridized overnight at $55^{\circ} \mathrm{C}$. On the next day, the embryos were washed and probes detected using alkalinephosphatase-conjugated antibody against digoxygenin and the subsequent colorimetric reaction with 4-nitrobluetetrazolium/5-bromo-4-chloro-3-indolyl phosphate (NBT/ BCIP; Roche Molecular Biochemicals, Indianapolis, IN). The color reaction was allowed to proceed for approximately 60 minutes and stopped with PBS. The embryos were then transferred to single concavity slides (Tri-Ess Sciences, Inc., Burbank, CA) and coverslipped for inspection and photography. Animals were sacrificed at 25, 31, 38 , and $48 \mathrm{hpf}$. Ten animals were processed per time point.

In situ hybridization with single probes on sections was performed as previously described (Hitchcock et al., 2001). Briefly, full-length neuroD cDNA (Korzh et al., 1998) was linearized and digoxygenin (DIG)-labeled riboprobes were synthesized with an RNA labeling kit (Roche Diagnostic Corp., Indianapolis, IN). After prehybridization, $200 \mathrm{ng}$ of probe in $80 \mu \mathrm{l}$ of hybridization solution was pipetted onto each slide, coverslipped, and hybridized overnight at $55^{\circ} \mathrm{C}$. On the next day, the sections were washed and DIG was immunolabeled with an alkaline-phosphatase-conjugated antibody and visualized with NBT/BCIP. The slides were then coverslipped for microscopy or combined with several immunocytochemistry protocols described below. Animals were killed at 25, 31, 38, 48, 60, 76, and $96 \mathrm{hpf}$ as well as at 3 months. Ten animals were analyzed per time point. NeuroD sense probes served as negative controls for all in situ hybridization protocols. After hybridization with neuroD sense probes, no staining was observed (data not shown).

Double in situ hybridization on sections was performed with probes for neuroD and red opsin or Crx. The protocol was modified from the one described above (see also Hitchcock and Kakuk-Atkins, 2004). Fluorescein-labeled riboprobes for red opsin and Crx were synthesized and used at a dilution of 1:500. Combinations of probes for neuroD and red opsin or for neuroD and Crx were diluted in buffer and hybridized simultaneously on the sections. After posthybridization washes, sections were immunostained with antibodies against DIG conjugated to alkaline phosphatase and antibodies against fluorescein conjugated to peroxidase. The sections were rinsed, and neuroD probes were visualized with fast red (Roche Diagnostic Corp., Indianapolis, IN) as the substrate. After further rinses, red opsin or Crx probes were visualized by using the Tyramide Signal Amplification Kit (Perkin Elmer, Nor- walk, CT) with streptavidin-Alexa Fluor 488 (Molecular Probes, Eugene, OR).

\section{BrdU labeling}

Bromodeoxyuridine (BrdU; Sigma, St. Louis, MO) was used to label mitotically active cells. Embryos were exposed to BrdU for 15 minutes by soaking in $5 \mathrm{mM}$ BrdU and $15 \%$ dimethylsulfoxide (DMSO) in embryo rearing solution (protocol adapted from Steve Devoto, University of Oregon; http://zebra.biol.sc.edu/methods/brdu.html) and killed immediately after BrdU exposure. Ten animals were analyzed per time point. Additional animals were exposed to BrdU for 15 minutes at $56 \mathrm{hpf}$ and killed 8 hours or 40 hours later. After BrdU exposure, these animals were housed in $10 \mathrm{mM}$ thymidine in embryo rearing solution to prevent continuous labeling of cells with accumulated systemic BrdU. Ten animals were analyzed.

\section{Immunocytochemistry}

All immunocytochemistry protocols were performed as previously described (Hitchcock et al., 1996). Omitting primary antibodies provided negative controls. In the absence of primary antibodies, no staining was observed (data not shown). Amacrine cells were labeled by using the cell-type-specific monoclonal antibody against rat syntaxin (monoclonal antisyntaxin clone HPC-1; Sigma; catalog S0664) and a monoclonal antibody against the human neuronal protein $\mathrm{HuC} / \mathrm{D}$ (formerly 16A11; Molecular Probes; catalog A21271; Kay et al., 2001), diluted 1:200, and a rabbit polyclonal antibody against mouse Pax6, diluted 1:1,000 (Covance, Berkeley, CA; lot 14811801; Hitchcock et al., 1996). The syntaxin antibody was raised in mouse against a synaptosomal plasma membrane fraction from adult rat hippocampus and on Western blot binds a $35-\mathrm{kD}$ protein. The $\mathrm{Hu}$ antibody was raised in mouse against the synthetic peptide QAQRFRLDNLLN, corresponding to amino acids $240-251$ of human $\mathrm{HuD}$ peptide, and on Western blot binds $36-\mathrm{kD}, 40-\mathrm{kD}$, and $42-\mathrm{kD}$ proteins corresponding to ELAVL2, ELAVL3, and ELAVL4, respectively. The pax6 antibody was raised in rabbit against the synthetic peptide REEKLRNQRRQASNTPSHI, corresponding to amino acids 281-299 of mouse Pax6, and on Western blot binds a $47-\mathrm{kD}$ protein and can be blocked with Pax 6 peptide. Cone photoreceptors were labeled with the mouse monoclonal antibody zpr-1 (The Zebrafish International Resource Center, Eugene, OR; catalog 092502) and diluted 1:200. The zpr-1 (formerly Fret43; Larison and Bremiller, 1990) and zpr-3 (see below) antibody was raised in mouse against a mix of antigens from 2-day-old whole zebrafish embryos, followed by selection for tissue/cell-specific binding of antibodies. The zpr1 antibody labels an unidentified epitope on red/ green cones. Rod photoreceptors were labeled with the mouse monoclonal antibody zpr-3 (The Zebrafish International Resource Center; catalog 011604) and diluted 1:200. The zpr-3 (formerly Fret11; Schmitt and Dowling, 1996) antibody labels an unidentified epitope on rod photoreceptors. On Western blots, Fret 11 binds a 38-kD protein and displays a banding pattern typical of antibodies possessing specificity for opsin proteins, including rhodopsin. BrdU was detected with a monoclonal antibody against BrdU (Becton Dickinson Immunocytochemistry Systems, San Jose, CA; catalog 347580) diluted 1:200. For doubleimmunocytochemistry experiments combining zpr-1 or zpr-3 and BrdU, the tissue was processed for zpr-1 or zpr-3 

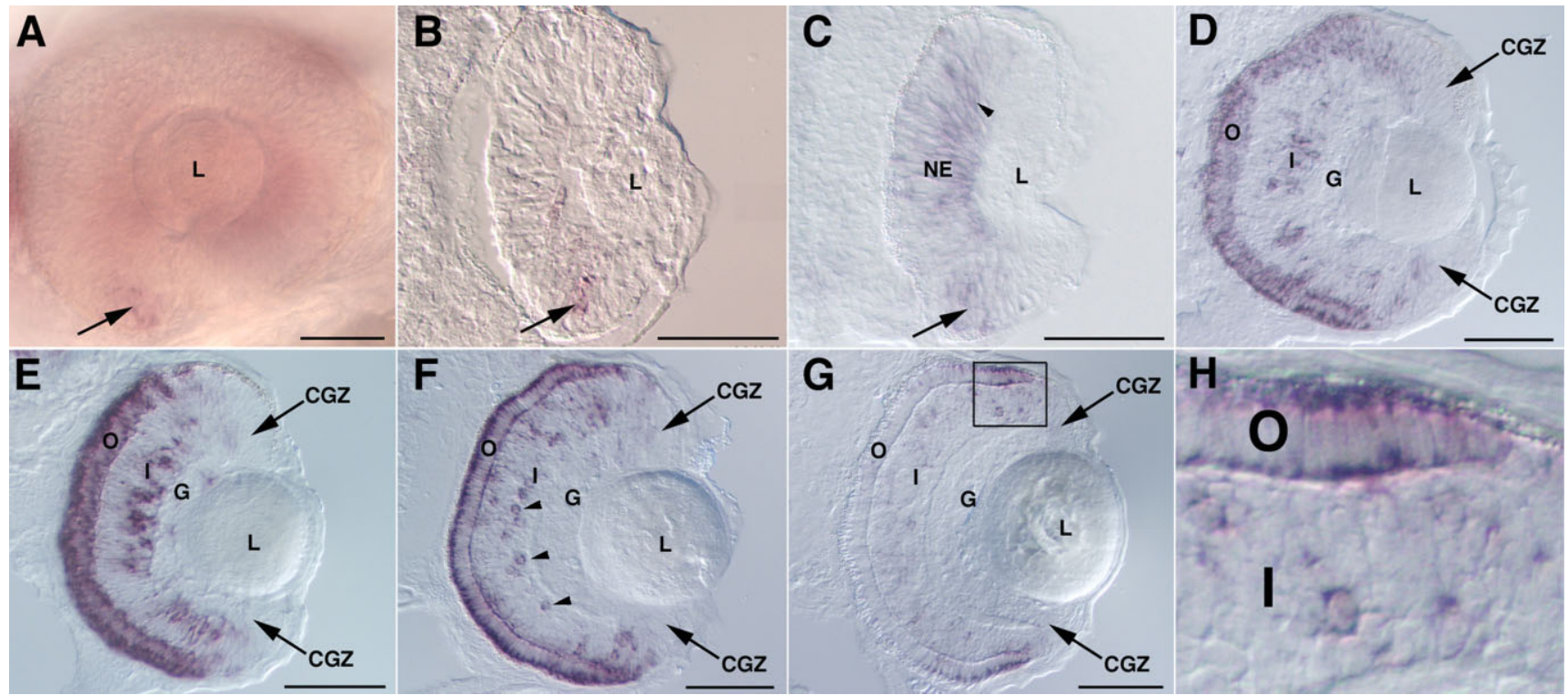

Fig. 1. Cellular pattern of neuroD expression in the developing retina of the zebrafish. A: neuroD expression at 31 hours post fertilization (hpf; arrow). B: Transverse section of a 31-hpf retina showing cells expressing neuroD (arrow). C: neuroD expression at $38 \mathrm{hpf}$ spanning the neuroepithelium and persisting in the ventral retina (arrow), arrowhead indicates an individual neuroD-expressing cell with neuroepithelial morphology. D: neuroD expression at $48 \mathrm{hpf}$. E: neuroD expression at $60 \mathrm{hpf}$. F: neuroD expression at $76 \mathrm{hpf}$,

arrowheads indicate neuroD-expressing amacrine cells. G: neuroD expression at $96 \mathrm{hpf}$ and in the retina margin (see $\mathbf{H}$; higher magnification of the boxed area in G). Note that neuroD is not expressed in the circumferential germinal zone (arrows in D-G). O, outer nuclear layer; I, inner nuclear layer; G, ganglion cell layer; L, lens; CGZ, circumferential germinal zone; NE, neuroepithelium. Scale bars $=50$ $\mu \mathrm{m}$.

antibody staining first, fixed a second time in $4 \%$ paraformaldehyde in phosphate buffer, and then processed for BrdU immunocytochemistry with a rat monoclonal antibody (Abcam, Cambridge, MA) diluted 1:200. All secondary antibodies conjugated to fluorescent labels were diluted 1:200.

\section{Photography}

Histological sections and whole mounts were photographed with a Nikon DMX 1200 digital camera. Digital overlays and figures were assembled in Adobe Photoshop 7.0 .

\section{RESULTS \\ Expression pattern of neuroD in embryonic and larval retinas}

NeuroD is first expressed at $31 \mathrm{hpf}$ in a small cluster of cells in the ventronasal retina (Fig. 1A,B). This location corresponds to a small patch of retina that in teleosts differentiates precociously (Schmitt and Dowling, 1999; $\mathrm{Hu}$ and Easter, 1999). At this stage, however, both the ventral patch and the remainder of the retina are an undifferentiated neuroepithelium, consisting largely of mitotically active cells. The neuroD-expressing cells in the precocious ventral patch are proliferative and are labeled with BrdU following a brief exposure (data not shown).

Between $31 \mathrm{hpf}$ and $48 \mathrm{hpf}$, neuroD expression expands from the ventronasal patch throughout the retinal neuroepithelium, which in a frontal plane appears to spread from ventral to dorsal (Fig. 1C). At this stage, all the neuroD-expressing cells are mitotically active (data not

shown). By 48 hpf, retinal laminae can be distinguished, and at this time neuroD expression segregates into the nascent inner and outer nuclear layers (Fig. 1D; see also Mueller and Wullimann, 2002), although the lamination in the dorsalmost retina is markedly less advanced, and neuroD expression there is reminiscent of that seen at earlier stages. The circumferential germinal zone at the retinal margin is first recognizable at $48 \mathrm{hpf}$, and it is noteworthy that at no time is neuroD expressed in these cells (Fig. 1D-G).

Between $48 \mathrm{hpf}$ and $76 \mathrm{hpf}$, neuroD continues to be expressed in both the inner and the outer nuclear layers. By $60 \mathrm{hpf}$, neuroD-expressing cells appear as clusters in the inner nuclear layer and as a relatively thick row of cells in the outer nuclear layer (Fig. 1E). This is also the stage when a population of large, presumptive amacrine cells that express neuroD first appears in the inner nuclear layer (Fig. 1E,F; see also Fig. 3). By 76 hpf, lamination is complete (Schmitt and Dowling, 1999; Li et al., 2000). At this stage, neuroD-expressing cells continue to be present in both the inner and the outer nuclear layers, although the neuroD-expressing cells in the inner nuclear layer are less dense than at $60 \mathrm{hpf}$ (compare Fig. 1E and F).

Between $76 \mathrm{hpf}$ and $96 \mathrm{hpf}$, the vast majority of cells within the outer nuclear layer cease expressing neuroD, and outer nuclear layer expression becomes restricted to the annulus of immature retina adjacent to the circumferential germinal zone (Fig. $1 \mathrm{G}, \mathrm{H}$ ). A few mitotically active, neuroD-expressing cells are still present within the outer nuclear layer. Within the inner nuclear layer, two populations of neuroD-expressing cells persist, presumptive 


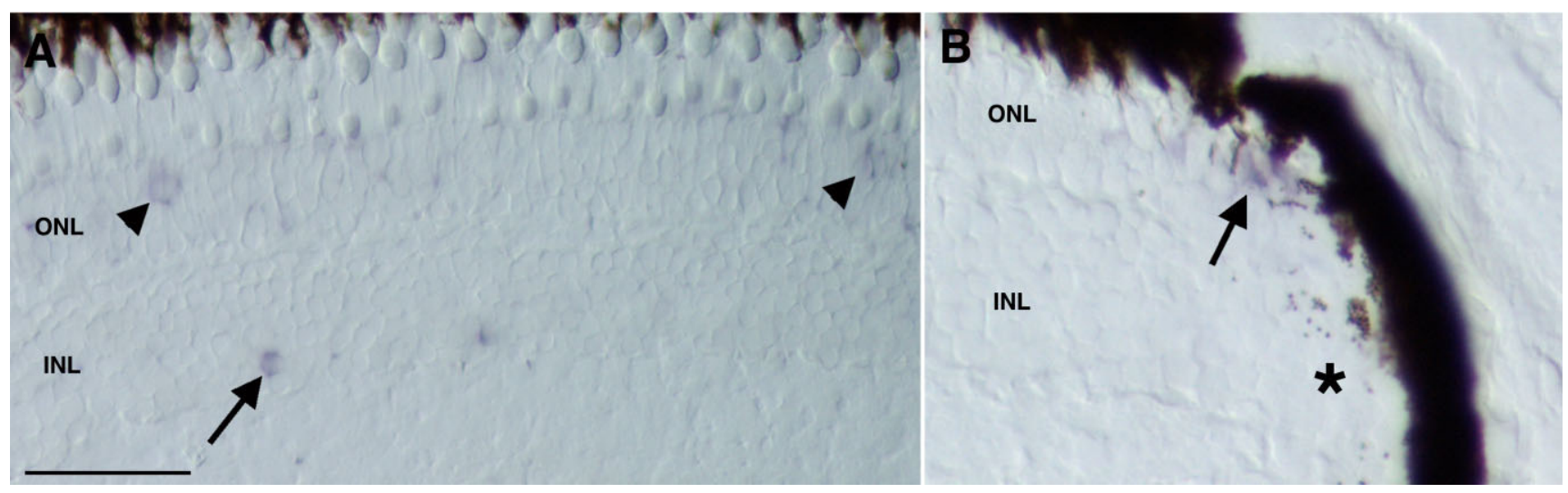

Fig. 2. Cellular pattern of neuroD expression in the adult zebrafish. A: neuroD expression in central retina showing a labeled amacrine cell (arrow), and presumptive cells of the rod lineage (arrowheads). B: neuroD expression at the retinal margin showing la- beled nascent cone photoreceptors (arrow). ONL, outer nuclear layer; INL, inner nuclear layer; asterisk, circumferential germinal zone. Scale bar $=50 \mu \mathrm{m}$. neurons and rare mitotic cells. At 96 hpf (Fig. 1G), the cellular neuroD expression achieves an adult-like pattern and remains unchanged from this stage onward (Fig. 2; see also Hitchcock and Kakuk-Atkins, 2004).

\section{NeuroD is expressed in both postmitotic and mitotic cell populations}

Amacrine cells. Three amacrine cell markers were used to establish the identity of the postmitotic cell types that express neuroD. Beginning at $76 \mathrm{hpf}$ neuroD is expressed in a subset of cells in the inner nuclear layer that, by virtue of their morphology and location, are identified as presumptive amacrine cells (Fig. 1F, arrowheads; see also insets in Fig. 3A,C). These cells have large somata, reside in the inner half of the inner nuclear layer, and are uniformly spaced across the retinal section. To confirm the identity of these cells, in situ hybridization for neuroD expression was combined with immunocytochemistry with antibodies against markers of amacrine cells, syntaxin, pax6, and HuC/D. Antibodies against syntaxin label the cytoplasm of amacrine cells, whereas antibodies against the transcription factor pax6 label nuclei (Fig. 3; see also Hitchcock et al., 1996). The antibody against HuC/D labels the cytoplasm of a subset of amacrine in the retina (see also Kay et al., 2001). All three markers, when combined with in situ hybridization using probes for neuroD, show that the large, neuroD-expressing cells in the inner nuclear layer are amacrine cells (Fig. 3 ). The majority of the neuroD-expressing cells with the morphology described above colabel with syntaxin, pax6, or $\mathrm{HuC} / \mathrm{D}$.

Nascent cone photoreceptors. Cone photoreceptors are the first cell type to differentiate as neurogenesis progresses within the outer nuclear layer (Branchek and Bremiller, 1984; Raymond and Barthel, 2004), and, in the adult retina, neuroD is not expressed by rods (Fig. 2; Hitchcock and Kakuk-Atkins, 2004). This suggests that, between $48 \mathrm{hpf}$ and $96 \mathrm{hpf}$, neuroD expression within the outer nuclear layer is restricted to differentiating cone photoreceptors and mitotically active photoreceptor progenitors. To confirm that neuro $D$ is expressed by nascent cone photoreceptors, sections from retinas at $76 \mathrm{hpf}$ were processed for double in situ hybridization for neuroD and red opsin, a marker for one of the first cone types to differentiate (Larison and Bremiller, 1990). This revealed that the vast majority of neuroD-expressing cells in the outer nuclear layer are cones (Fig. 4A-C, arrow). Furthermore, there appears to be a discrete boundary between cells in the outer nuclear layer that express neuroD only and those that express both neuroD and red opsin (Fig. 4A-C, arrowhead). This double-labeling approach clearly demarcates the region of cone genesis and maturation, which lies between the circumferential germinal zone and the first neuroD/red opsin-expressing cones (Fig. 4C).

Cells of the rod lineage. We used BrdU combined with double-labeling methods to determine the identity of the mitotic cells that express neuroD. After the initial waves of neurogenesis and lamination, mitotically active cells remain within both the inner and the outer nuclear layers. Based on data from studies of retinas from adult teleosts, it is inferred that, in the larval retina, these dividing cells are members of the rod lineage. Rod genesis in adult teleosts has been extensively described (for review see Hitchcock and Raymond, 2004), and the rod lineage consists of dividing cells in both the inner and the outer nuclear layers. NeuroD is expressed by a population of cells in the inner nuclear layer not labeled with amacrine cell markers. These cells are characterized by a neuroepithelial morphology (Fig. 5c1, arrow), resembling the morphology of the neuroD-expressing cells found in the 38-hpf embryonic retina (compare arrowhead in Fig. $1 \mathrm{C}$ and arrow in Fig. 5c1), and they are proliferative as evidenced by their labeling with BrdU (Fig. 5C; arrow in $\mathrm{c} 1$ and c2). Between $48 \mathrm{hpf}$ and $76 \mathrm{hpf}$, neuroD is also expressed in proliferating cells in the outer nuclear layer. These cells can be labeled with BrdU and are interspersed among the orderly arrangement of cone nuclei (Fig. 5C; arrow in c3-c4).

To confirm the identity of these mitotically active cells, retinas were exposed to BrdU at $56 \mathrm{hpf}$, animals were killed at $96 \mathrm{hpf}$, and retinas were double labeled with antibodies to BrdU and zpr-3, a marker of rod photoreceptors. This revealed that at 56-hpf mitotically active cells in the laminated retina give rise to rod photoreceptors (Fig. 6 ). It should be noted, however, that only a minority of 


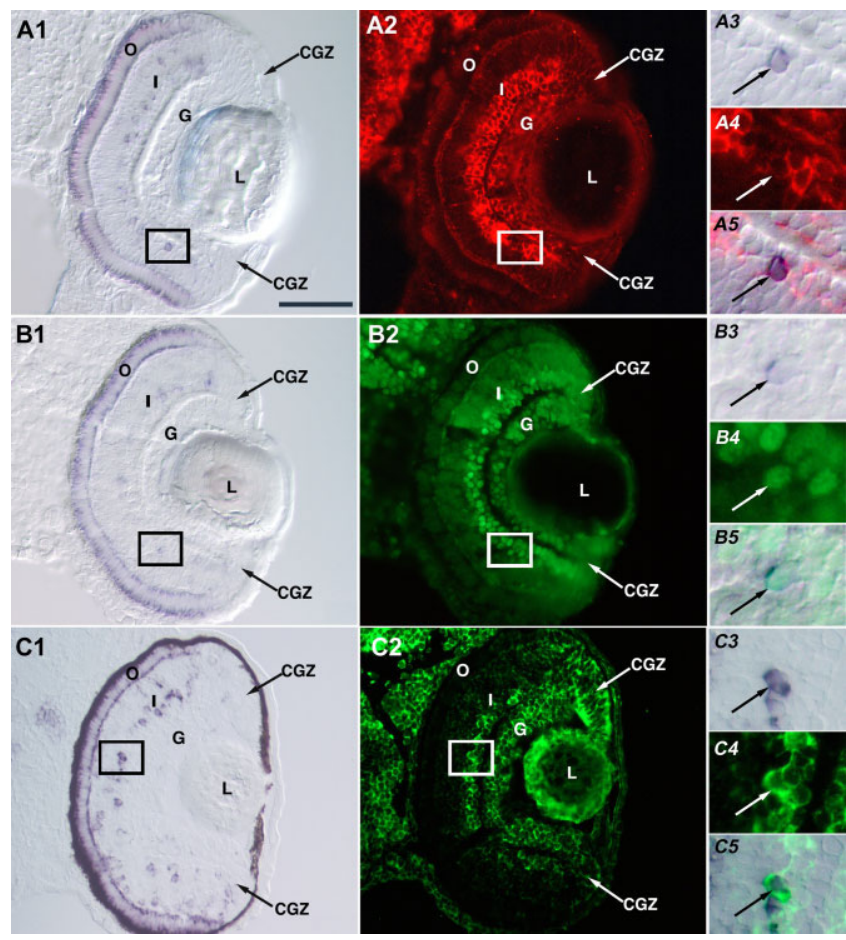

Fig. 3. neuroD is expressed in a subset of amacrine cells in the inner nuclear layer. A1,2: At 76 hours post fertilization (hpf), neuroDexpressing cells in the inner nuclear layer (INL) colabel with antibodies against syntaxin (A). A3: The arrow indicates an individual neuroD-expressing cell in the INL. A4: The arrow indicates the same cell as in A3, labeled with syntaxin. A5: Overlay of neuroD and syntaxin shown in A3 and A4. The arrow indicates the same cell shown in A3 and A4, which both expresses neuroD and is labeled with syntaxin. B1,2: neuroD-expressing cells in the INL colabel with antibodies against pax6 (B). B3: The arrow indicates an individual neuroD-expressing cell in the INL. B4: The arrow indicates the same cell as in B3, labeled with pax6. B5: Overlay of neuroD and pax6 shown in B3 and B4. The arrow indicates the same cell shown in B3 and B4, which both expresses neuroD and is labeled with pax6. C1,2: neuro $D$-expressing cells in the INL colabel with antibodies against HuC/D (C). C3: The arrow indicates an individual neuroDexpressing cell in the INL. C4: The arrow indicates the same cell as in C3, labeled with HuC/D. C5: Overlay of neuroD and HuC/D shown in C3 and C4. The arrow indicates the same cell shown in C3 and C4, which both expresses neuroD and is labeled with HuC/D. O, outer nuclear layer; I, inner nuclear layer; G, ganglion cell layer; L, lens; CGZ, circumferential germinal zone. Scale bar $=50 \mu \mathrm{m}$.

cells labeled with BrdU at 56 hpf expresses zpr-3 at $96 \mathrm{hpf}$. We interpret this to show that not all cells of the rod lineage become fully differentiated during the interval that we examined and therefore remain labeled with BrdU but do not yet express zpr-3. These observations suggest that, as in the adult teleost retina, neuroD is expressed in the rod photoreceptor lineage in the developing teleost retina.

Cone progenitors. We also evaluated neuroD expression among cells that give rise to cone photoreceptors. Although visual inspection of the outer nuclear layer, based on morphology and markers of differentiated cells, suggests that cone genesis in the central retina ceases by 76 hpf (see Figs. 1F , 4), we cannot exclude the possibility that the outer nuclear layer contains mitotically active cells that express neuroD and give rise to cones. To deter- mine whether cones are generated in central retina during this time, animals were exposed to BrdU at $56 \mathrm{hpf}$ and sacrificed at $64 \mathrm{hpf}$. The retinas were then doubly labeled with antibodies against BrdU and zpr-1, a marker of cone photoreceptors. These experiments showed that cones are still being generated in central retina at this time (Fig. 7), which raises the possibility that some BrdU-positive, neuroD-expressing cells give rise to cones.

To determine more directly whether neuroD-expressing cells generate cones, we examined the junction between the circumferential germinal zone and the nascent outer nuclear layer, a site where dividing cells merge with the all-cone outer nuclear layer. We surmise that, by virtue of their position, the dividing cells here serve as cone progenitors (arrow in Fig. 8A,B; see also Stenkamp et al., 1997). To determine whether these cone progenitors express neuroD, animals were exposed to BrdU at $96 \mathrm{hpf}$ and processed for in situ hybridization with neuroD probes and BrdU immunohistochemistry. This revealed that the cells, which express neuroD and are contiguous with the allcone outer nuclear layer, are mitotically active (Fig. 8C,D). In addition to relying on position to identify cone progenitors, we performed double in situ hybridization with neuroD and red opsin probes combined with BrdU immunohistochemistry to identify stages of cone differentiation and neuroD expression (Fig. 8E-H). Mitotically active cells at the periphery begin expressing neuroD, and this expression is maintained in immature cones. As the cones mature and begin expressing red opsin, there is a small region of overlap of neuroD and red opsin expression. However, left of this transition point, neuroD expression is down-regulated in the more mature red opsin-expressing cells. Our observations suggests that neuroD is expressed in a small subset of cells within the circumferential germinal zone, perhaps during their ultimate or penultimate mitosis, serving exclusively as cone progenitors. By extension, because the retina periphery recapitulates development, we infer that, in the developing central retina, some dividing cells that express neuroD also give rise to cones. This analysis revealed that neuroD expression marks stages of cone development.

\section{NeuroD and the developmental regulatory gene $\boldsymbol{C r} \boldsymbol{x}$}

It is interesting to note that, along with neuroD, only one other developmental regulatory gene, cone-rod homeobox $(C r x)$, has been shown to be expressed among photoreceptor progenitors in the zebrafish retina (Shen and Raymond, 2004). This coincidence of cellular expression suggests that neuroD and Crx may interact genetically, which can be tested experimentally. To confirm whether neuroD and $C r x$ are expressed in the same cells, sections from retinas at $76 \mathrm{hpf}$ were processed for double in situ hybridization for neuroD and Crx. This revealed that the vast majority of neuroD-expressing cells in the outer nuclear layer also expresses Crx (Fig. 9). Furthermore, whereas neuroD and $C r x$ are coexpressed in the outer nuclear layer, there is no colocalization of $C r x$ and neuroD expression in the inner nuclear layer. Crx expression is restricted to the outer part of the inner nuclear layer, whereas neuroD expression is localized to the middle and inner part of the inner nuclear layer (Fig. 9E-H). 


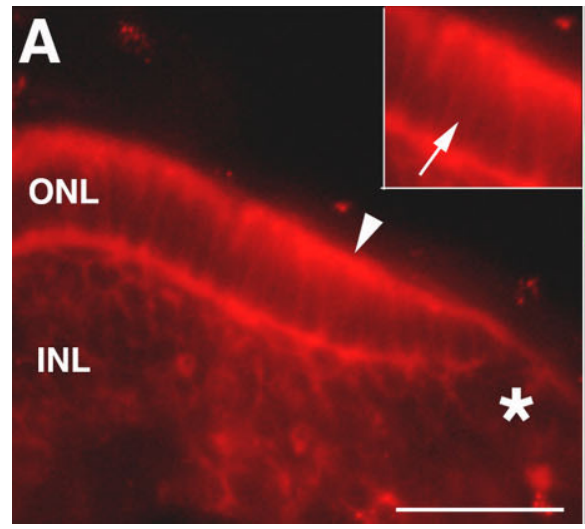

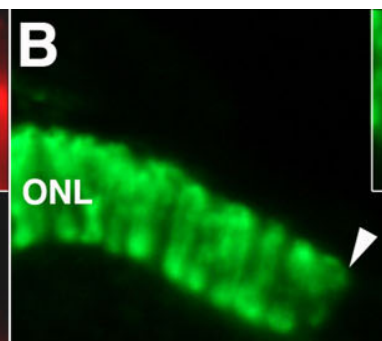

INL
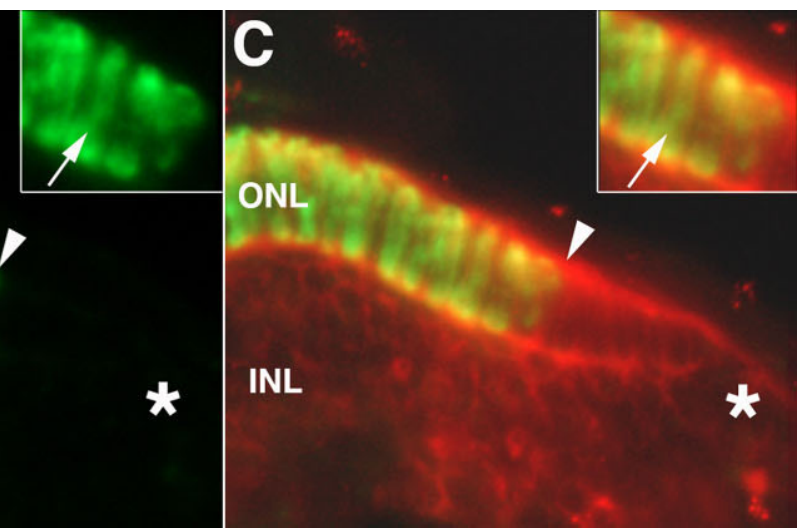

Fig. 4. neuroD is expressed in nascent cone photoreceptors. A: Retina at 76 hours post fertilization (hpf) labeled with a neuroD probe. Cells throughout the outer nuclear layer (ONL) express neuroD, and the arrow indicates an individual neuro $D$-expressing cell (see inset in C). B: Cells in the ONL labeled with a probe for red opsin. The arrow indicates an individual red opsin-expressing cell (see inset in B). C: Overlay of neuroD and red opsin in situ shown in A and B. Cells in the ONL coexpress neuroD and red opsin. The arrow indicates the same cell shown in $\mathrm{A}$ and $\mathrm{B}$, which expresses both neuroD and red opsin (see inset in C). The arrowhead in all figures depicts the transition between cones in the ONL expressing neuroD only and those that express both neuroD and red opsin. The asterix indicates the CGZ. ONL, outer nuclear layer; INL, inner nuclear layer; CGZ, circumferential germinal zone. Scale bar $=50 \mu \mathrm{m}$
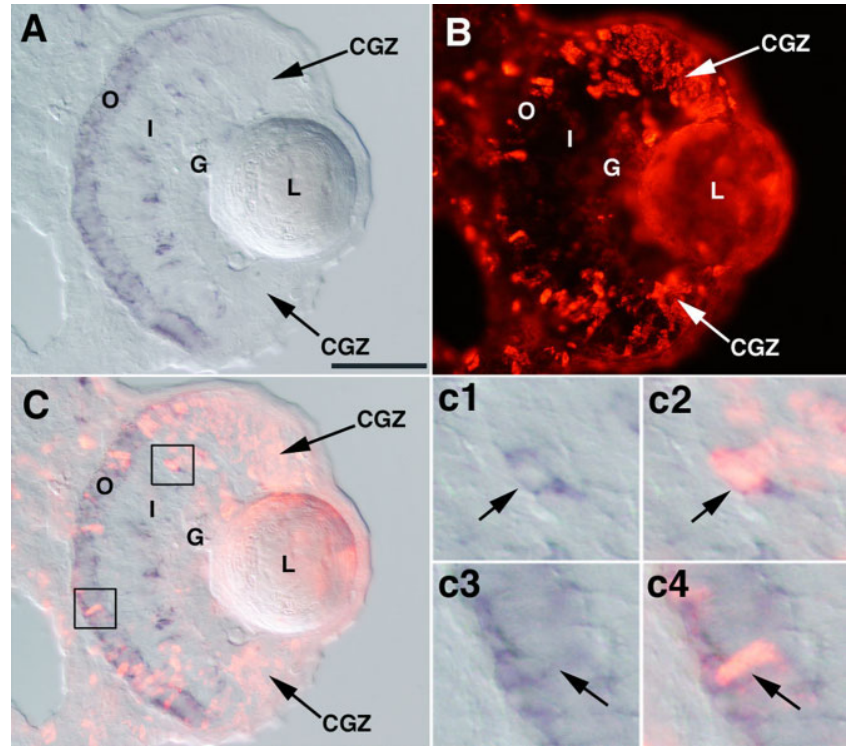

Fig. 5. neuroD is expressed in cells of the rod photoreceptor lineage. A,B: 76 hours post fertilization (hpf) retina showing neuroD in situ (A) and BrdU immunohistochemistry (ICC; B). C: Overlay of neuroD in situ and BrdU ICC. c1,2: Rod progenitors in the inner nuclear layer (INL) are characterized by neuroepithelial morphology and BrdU incorporation (see arrow in c2). c3,4: Rod precursors in the outer nuclear layer (ONL) are characterized by BrdU incorporation and morphology (see arrow in $\mathrm{c} 4$ ). Note the absence of neuroD expression in the mitotically active multipotent progenitors in the circumferential germinal zone (CGZ; arrows in C). O, outer nuclear layer; I, inner nuclear layer; G, ganglion cell layer; L, lens; CGZ, circumferential germinal zone. Scale bar $=50 \mu \mathrm{m}$.

\section{DISCUSSION}

The cellular expression of neuroD in the teleost retina is dynamic and spans early neurogenesis, the maturation of cone photoreceptors, and the acquisition of the adult pat- tern, which in zebrafish is present by at least $96 \mathrm{hpf}$. The current study further suggests that neuroD is expressed in two separate lineages that give rise to rod and cone photoreceptors, respectively, and is transiently expressed in differentiated cones, suggesting that this gene may play a role in the maturation of this cell type. The expression data further indicate that neuroD is coexpressed with $C r x$ in cells in the developing photoreceptor layer, raising the possibility that, as in mammals (Akagi et al., 2005), these transcriptional regulators interact genetically.

During early retinogenesis (31-48 hpf) neuroD is expressed in cells of the proliferative neuroepithelium. Although variable in age of onset (see Korzh et al., 1998; Masai et al., 2000), neuro $D$ expression is first observed in ventronasal retina. Numerous studies have shown that in teleosts the ventronasal patch of retina develops precociously (Raymond et al., 1995; Schmitt and Dowling, 1999; $\mathrm{Hu}$ and Easter, 1999), and the localized onset of neuroD expression in this patch presages local, precocious differentiation. In the larval and adult retinas, neuroD is expressed in cells of the rod lineage (Hitchcock and KakukAtkins, 2004; present results), and the expression of neuroD in the ventronasal patch suggests that the photoreceptors generated there originate from the same cellular lineage that generates rods at later developmental and adult stages (see Discussion in Raymond et al., 1995).

As retinogenesis progresses, the expression of neuroD expands from the precocious patch throughout the remaining retinal neuroepithelium. The neuroepithelial cells that express neuroD at this stage may correspond to photoreceptor progenitors, which give rise to the cells that establish the future outer nuclear layer. Thus, after the differentiation of cells in the ventral patch, mitotically active cells that express neuroD may be destined to become either cone or rod photoreceptors. The expanding neuroD expression across the developing neuroepithelium might also mark the formation of the lineages that give rise to rods and cones in central retina.

As neurogenesis continues and laminae appear (48-96 $\mathrm{hpf}$ ), neuroD expression segregates to the inner and outer 

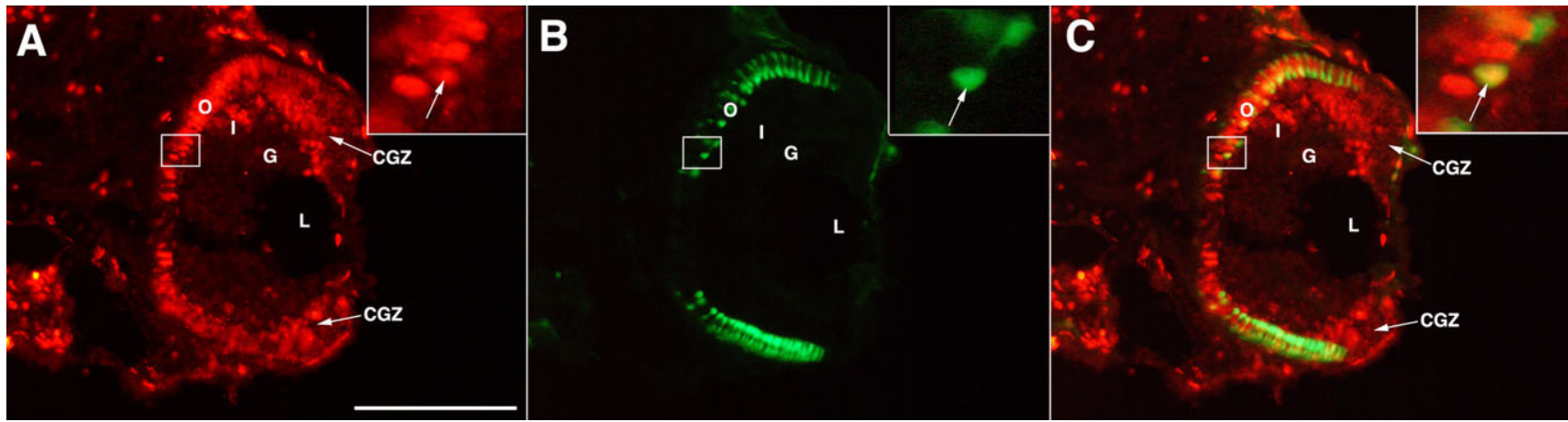

Fig. 6. BrdU-labeled cells in the outer nuclear layer give rise to rod photoreceptors. A,B: 96 hours post fertilization (hpf) retina exposed to BrdU at $55 \mathrm{hpf}$ and sacrificed at $96 \mathrm{hpf}$ showing BrdU labeling (A) and zpr-3 staining (B), respectively. Insets in A and B depict an individual cell in the outer nuclear layer (ONL) labeled with BrdU and zpr-3, respectively. C: Overlay of BrdU and zpr-3 immuno- histochemistry shown in A and B. Inset in C shows one BrdU-positive cell in the ONL colabeled with BrdU and zpr-3 (arrow). Note that most of the cells in the ONL are not colabeled with BrdU and zpr-3. O, outer nuclear layer; I, inner nuclear layer; G, ganglion cell layer; L, lens; CGZ, circumferential germinal zone. Scale bar $=50 \mu \mathrm{m}$
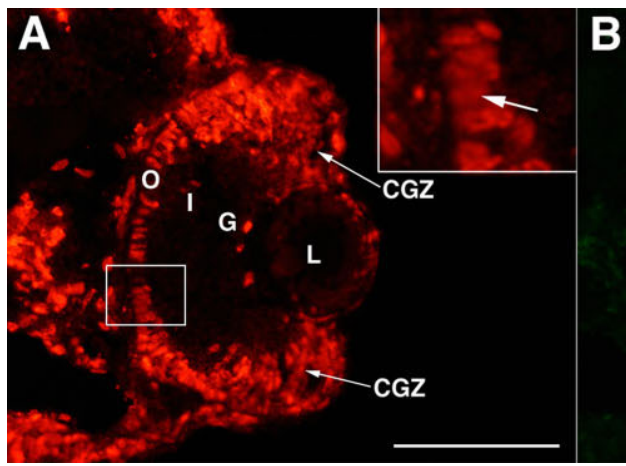

Fig. 7. BrdU labels cone progenitors in the outer nuclear layer A,B: 64 hours post fertilization (hpf) retina exposed to BrdU at $56 \mathrm{hpf}$ and sacrificed at $64 \mathrm{hpf}$ showing BrdU labeling (A) and zpr-1 staining (B), respectively. Insets in A and B depicts an individual cell in the outer nuclear layer (ONL) labeled with BrdU and zpr-1, respectively.

nuclear layers, marking four different cell types, two postmitotic and two mitotic. The two postmitotic cell types that express neuroD are amacrine cells and nascent cone photoreceptors. In the inner nuclear layer, neuroD is expressed in a small subset of postmitotic amacrine cells. This was speculated upon previously (Hitchcock and Kakuk-Atkins, 2004) and confirmed here by using a double-labeling approach. However, even though all amacrine antibodies used have been well characterized in the literature and label subsets of mature amacrine cells, in other neural tissues these antibodies label neural progenitors. We cannot exclude the possibility that some of the double-labeled cells with amacrine morphology correspond to progenitor cells (see below). In the outer nuclear layer, neuroD is expressed by nascent cone photoreceptors. This is demonstrated directly via double in situ hybridization at $76 \mathrm{hpf}$, which reveals that most neuroDexpressing cells in the outer nuclear layer at this time are cone photoreceptors. As the retina matures, the nascent cones in central retina down-regulate neuroD expression, and, by $96 \mathrm{hpf}$, neuroD is absent from central cones. Consistent with this temporal pattern, from $96 \mathrm{hpf}$ onward, expression is maintained in each cohort of immature cones
C: Overlay of BrdU and zpr-1 immunohistochemistry shown in A and $\mathrm{B}$. Inset in $\mathrm{C}$ shows one BrdU-positive cells in the ONL colabeled with BrdU and zpr-1 (arrow). O, outer nuclear layer; I, inner nuclear layer; $\mathrm{G}$, ganglion cell layer; L, lens; CGZ, circumferential germinal zone. Scale bar $=50 \mu \mathrm{m}$.

at the periphery. This indicates that neuroD expression in cones is transient, lasting for merely hours, and suggests that this gene may play a role in regulating an aspect of early cone maturation.

It is well established that, in the adult teleost, rod photoreceptors are generated by a lineage of proliferative cells that originates in the inner nuclear layer (Julian et al., 1998; Otteson et al., 2001), and these cells express neuroD (Hitchcock and Kakuk-Atkins, 2004). At $56 \mathrm{hpf}$ in the zebrafish, a time when neurogenesis is largely complete in the inner retina but photoreceptor genesis is still ongoing ( $\mathrm{Hu}$ and Easter, 1999), the inner nuclear layer of the zebrafish retina contains proliferative cells that express neuroD. We infer that these cells are rod progenitors, which give rise to the first generation of central rod photoreceptors (see also Raymond and Rivlin, 1987). This was confirmed here by labeling cells with BrdU and double immunostaining with antibodies against BrdU and zpr-3 (a marker of rod photoreceptors), which demonstrated the presence of BrdU-labeled rods.

The double-labeling approach also established that, in central retina at $56 \mathrm{hpf}$, cones are also being born. In teleosts, in general, cone genesis precedes rod genesis 


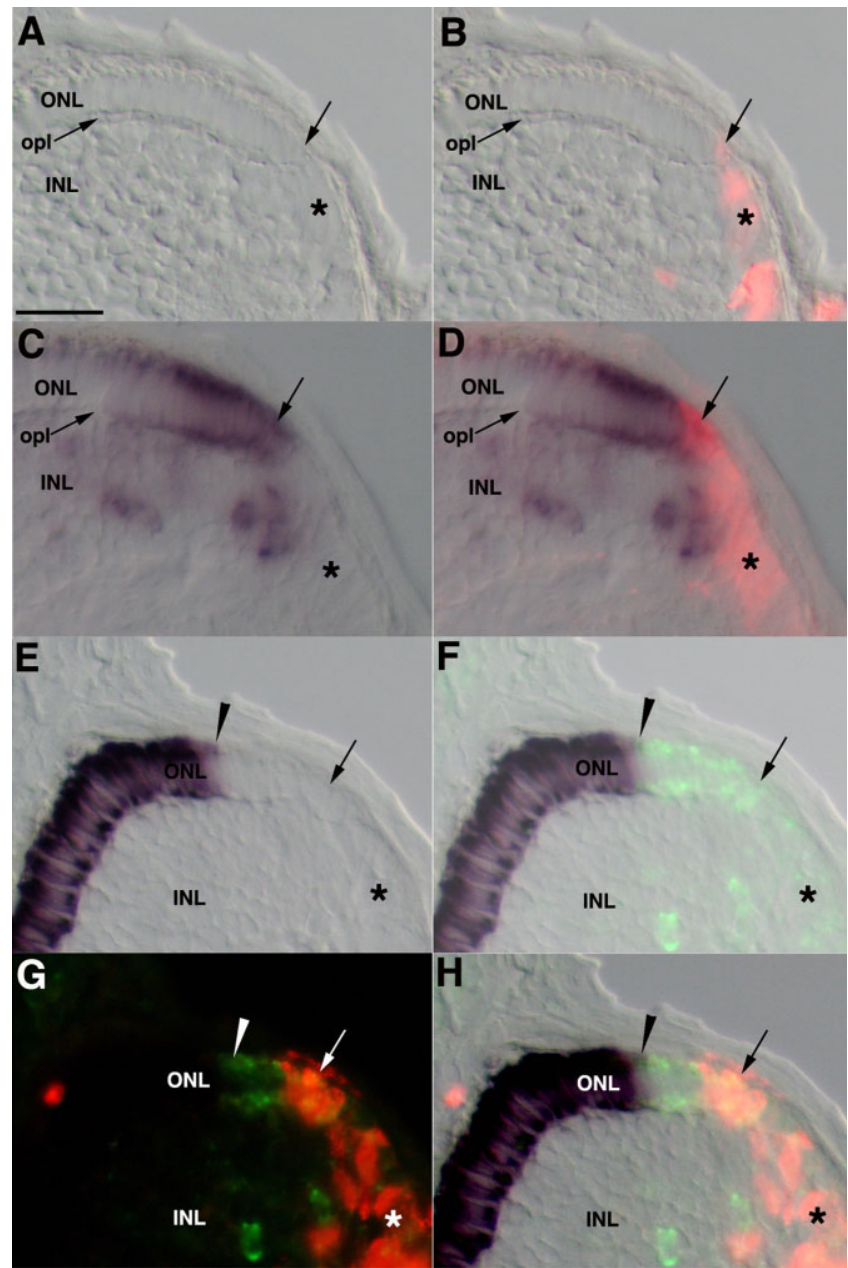

Fig. 8. neuroD is expressed in cone progenitors. A,B: Brightfield image of a 96 hours post fertilization (hpf) retina (A) and overlay with BrdU immunohistochemistry (B). Note the labeled BrdU-positive cells directly above the outer plexiform layer (arrow). C,D: $96 \mathrm{hpf}$ retina showing neuroD in situ (C) and overlay with BrdU immunohistochemistry (D). Arrows in both $\mathrm{C}$ and $\mathrm{D}$ depict an individual cell, which is doubly labeled with neuroD and BrdU. neuroD expression marks stages of cone development. E,F: 96 hpf retina showing red opsin in situ (E) and overlay with neuroD in situ (F), respectively. Arrowheads in $\mathrm{E}$ and $\mathrm{F}$ indicate an individual cell that coexpresses red opsin and neuroD. Note that, left of this transition point, marked by the arrowhead, neuroD expression is down-regulated in the more mature red opsin-expressing cells (see also C and D). G,H: The same retina as in $\mathrm{E}$ and $\mathrm{F}$, showing neuroD expression ( $\mathrm{G}$, green) and BrdU-positive cells $(\mathrm{G}$, red) and $(\mathrm{H})$ overlay with both red opsin and neuroD in situ from $\mathrm{E}$ and $\mathrm{F}$. Arrows in $\mathrm{E}-\mathrm{H}$ indicate an individual cell, which expresses neuroD and is BrdU positive. The asterisk indicates the CGZ. ONL, outer nuclear layer; INL, inner nuclear layer; CGZ, circumferential germinal zone. Scale bar $=50 \mu \mathrm{m}$.

(Johns, 1982), but there is an interval when in central retina of the zebrafish these two cell types are generated contemporaneously (Raymond et al., 1995; Schmitt and Dowling, 1999; see also Larison and Bremiller, 1990; present results). Our data show that, during this interval, there are numerous BrdU-positive cells in the retina that express neuroD. We speculated, based on these observations, that some dividing, neuroD-positive cells might also give rise to cone photoreceptors. Because at $56 \mathrm{hpf}$ one does not know whether a dividing cell in central retina will give rise to a cone or rod, we examined the germinative margin for evidence of dividing cells that both express neuro $D$ and occupy a location that indicates they serve as cone progenitors. We found such cells in the outer nuclear layer lying at the interface between the circumferential germinal zone and newly postmitotic cones. From this evidence we conclude that there exists a narrow annulus of proliferative, neuroD-expressing cells at the germinative margin that give rise exclusively to cone photoreceptors and that these cells express neuroD at the time of their ultimate or penultimate division. Furthermore, and by extension, we conclude that some dividing cells in central retina that express neuroD must also give rise to cones, including those cones first generated in the ventronasal patch.

These observations and our inferences from the data suggest one of two possibilities. First, in central retina, rod and cone lineages emerge separately from the neuroepithelium and separately generate the two photoreceptor types, or, second, during the interval when both cell types are generated, rods and cones share a common lineage or progenitor. The fact that, in the teleost retina, from early larval development through adulthood, rods and cones are generated from spatially separate progenitors argues in favor of the first possibility, that from the outset rods and cones are generated from separate cell lineages. In contrast, direct evidence from both birds and mammals suggests that rods and cones can share a common progenitor (Yan and Wang, 1998, 2000, 2004; Mears et al., 2001). Whether early photoreceptor genesis in teleosts fits the avian and mammalian model remains to be determined.

It has been suggested that cones and rods are produced simultaneously in the ventral patch, whereas the remainder of photoreceptors are formed during the final wave of terminal mitoses in the outer nuclear layer (Raymond and Barthel, 2004). It is interesting to note that another developmental gene, cone-rod homeobox $(\mathrm{Cr} x)$, is also expressed by mitotically active progenitors in the outer nuclear layer (Shen and Raymond, 2004). These data suggest that $C r x$ may be expressed in late-stage photoreceptor progenitors as they exit the cell cycle. Crx regulates differentiation and survival of retinal photoreceptors and may also play a role in promoting differentiation of retinal progenitors. Several studies demonstrate that bHLH factors function in concert with homeodomain genes during the patterning of the retina (Hatakeyama et al., 2001; Akagi et al., 2004). Our current data reveal that neuroD and $C r x$ are expressed in the same cells in the outer nuclear layer. This suggests that, in zebrafish, neuroD may interact with Crx during the genesis of photoreceptors, perhaps as progenitors exit the cell cycle, and that a similar genetic signaling cascade is present in both homeothermic vertebrates and teleosts.

Finally, the data from our study allow us to expand current models of photoreceptor genesis in the mature retina of teleost fish (Raymond and Rivlin, 1987; Otteson et al., 2001; Otteson and Hitchcock, 2003). We show that the rod lineage and associated neuroD expression, first described for adult goldfish (Hitchcock and Kakuk-Atkins, 2004), are present in the embryonic retina as early as 56 hpf in zebrafish and perhaps earlier (Fig. 10A). In addition, there is a narrow annulus of dividing cells at the germinative margin expressing neuroD and serving exclusively as cone progenitors (Fig. 10B). We suggest that, as 
bisbenzimide
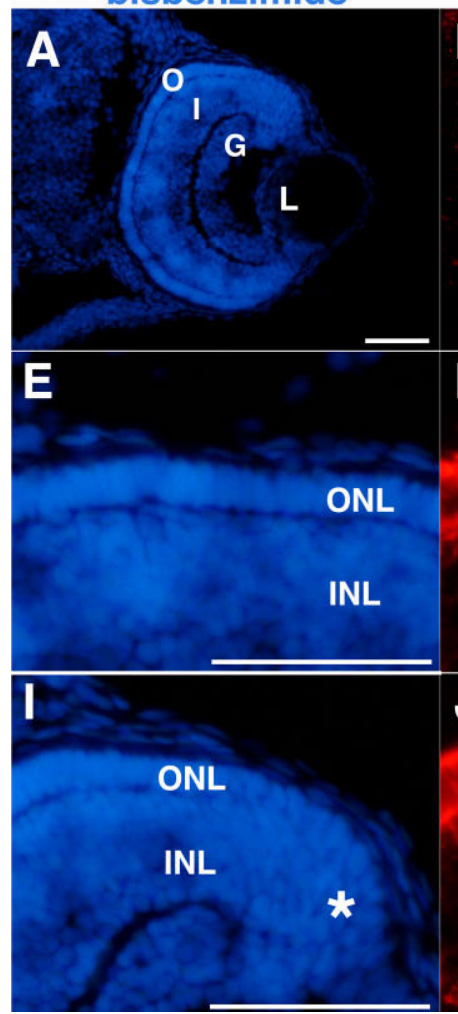

Fig. 9. neuroD and $C r x$ are coexpressed in nascent cone photoreceptors. A,E,I: Retina at 76 hours post fertilization (hpf) labeled with bisbenzimide. B,F,J: Retina at $76 \mathrm{hpf}$ labeled with a neuroD probe. Cells throughout the ONL express neuroD. C,G,K: Cells in the ONL labeled with a probe for Crx. Cells throughout the ONL express Crx. D,H,L: Overlay of neuroD and $C r x$ in situ shown in B,F,J and C,G,K,
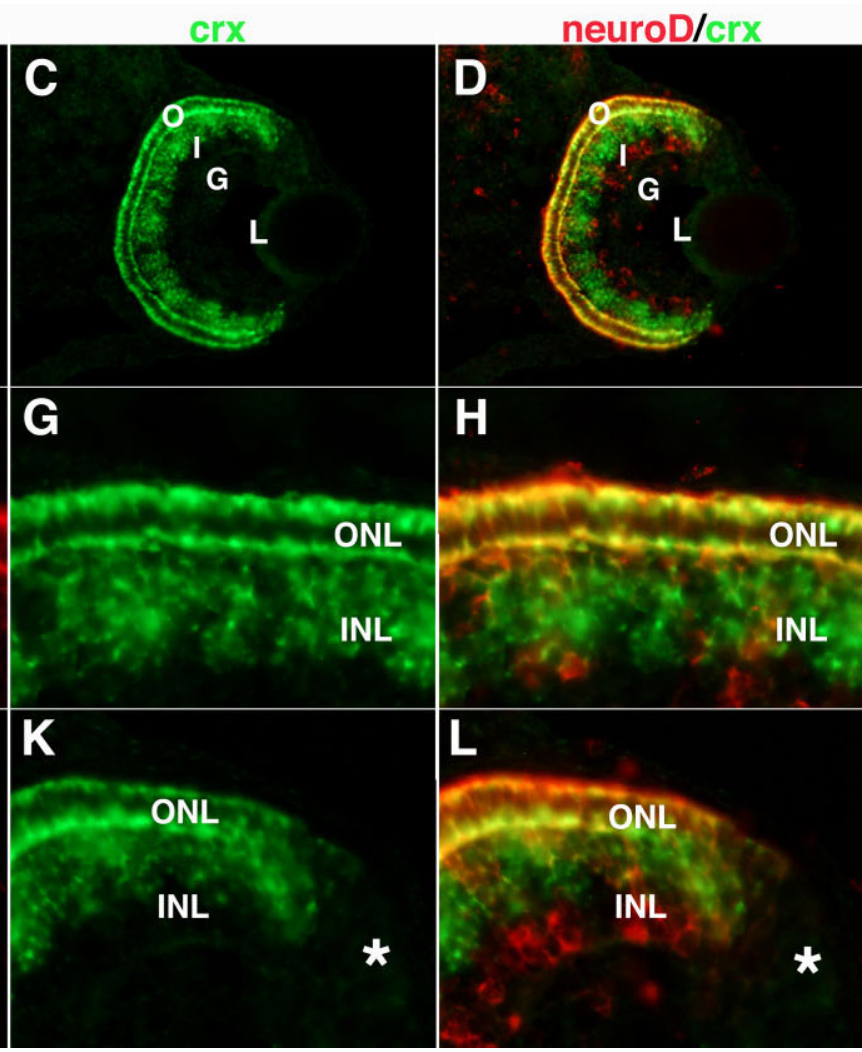

respectively. Cells in the ONL coexpress neuroD and $C r x$. The asterisk indicates the CGZ. ONL, outer nuclear layer; INL, inner nuclear layer; CGZ, circumferential germinal zone. Scale bars $=50 \mu \mathrm{m}$ in A (applies to A-D); $50 \mu \mathrm{m}$ in E (applies to $\mathrm{E}-\mathrm{H}$ ); $50 \mu \mathrm{m}$ in I (applies to I-L).

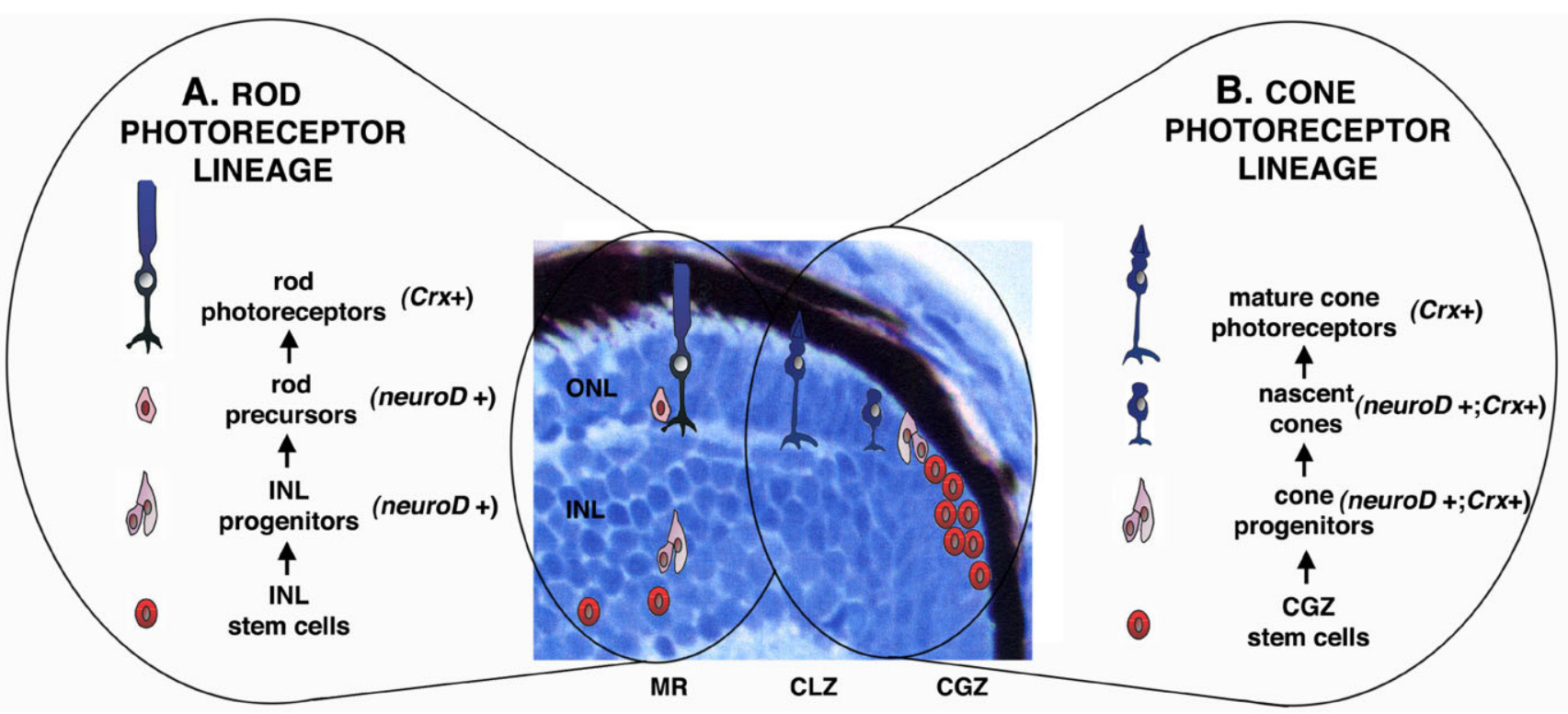

Fig. 10. Lineage model illustrating rod and cone genesis in the teleost retina. A: Lineage model of rod genesis. Inner nuclear layer (INL) stem cells give rise to neuroD-expressing INL progenitors, which traverse to the outer nuclear layer and give rise to neuroD expressing rod precursors, which give rise to rod photoreceptors that do not express neuroD but do express Crx. B: Lineage model of cone genesis. Circumferential germinal zone stem cells give rise to neuroD and $C r x$-expressing cone progenitors, which give rise to neuroD and Crx-expressing nascent cone photoreceptor, which give rise to mature cone photoreceptors that do not express neuroD but continue to express Crx. ONL, outer nuclear layer; GCL, ganglion cell layer; MR mature retina; CLZ, circumferential larval zone; CGZ, circumferential germinal zone. 
these cells express neuroD, they divide a limited number of times, perhaps only once, and then continue to express this gene for the first few hours of maturation. Our results also suggest that, by virtue of their spatial separation, with the teleost retina, one can separately assay the function of neuro $D$ in the lineages of cells that give rise to rods (centrally) and cones (at the germinative margin), respectively.

There is an expanding body of evidence pointing to a common role for neuroD in persistently mitotic cellular lineages, linking cell cycle withdrawal with terminal differentiation. The existence of a mitotic lineage generating a single cell type, such as the rod photoreceptor lineage, is not unique and is present in other persistently mitotic regions in the adult central nervous system, including cells in the subventricular zone and rostral migratory stream, dentate gyrus, and cerebellum (Miyata et al., 1999; Schwab et al., 2000; Pleasure et al., 2000; Lee et al., 2000; Bedard and Parent, 2004; Hevner et al., 2006; see also Naya et al., 1997; Mutoh et al., 1998; Schonhoff et al., 2004). In each of these regions, neuroD is expressed in late-stage progenitors, perhaps during their ultimate or penultimate mitosis, and appears to be essential for terminal differentiation. Current evidence thus suggests a common function of neuroD in cell lineages, and determining this function in the rod and cone lineages in the zebrafish retina may shed light on the overarching role that neuroD is playing in persistently mitotic tissues of adult vertebrates.

\section{ACKNOWLEDGMENTS}

The authors thank the following individuals for contributing to this study: Michelle Hardin and Regina Belaney for administrative assistance, members of the Hitchcock laboratory for reading earlier versions of the manuscript, Zhiyuan Gong (National University of Singapore) for providing the neuroD cDNA, Pamela Raymond (University of Michigan) for providing the red opsin and Crx cDNA, and the Zebrafish International Resource Center (ZFIN; grant P40 RR12546 from the NIH-NCRR) for providing the zpr-1 and zpr-3 antibodies.

\section{LITERATURE CITED}

Acharya HR, Dooley CM, Thoreson WB, Ahmad I. 1997. cDNA cloning and expression analysis of NeuroD mRNA in human retina. Biochem Biophys Res Commun 233:459-463.

Ahmad I, Acharya HR, Rogers JA, Shibata A, Smithgall TE, Dolley CM. 1998. The role of NeuroD as a differentiation factor in the mammalian retina. J Mol Neurosci 11:165-178.

Akagi T, Inoue T, Miyoshi G, Bessho Y, Takahashi M, Lee JE, Guillemot F, Kageyama R. 2004. Requirement of multiple basic helix-loop-helix genes for retinal neuronal subtype specification. J Biol Chem 279: $28492-28498$.

Akagi T, Akita J, Haruta M, Suzuki T, Honda Y, Inoue T, Yoshiura S, Kageyama R, Yatsu T, Yamada M, Takahashi M. 2005. Iris-derived cells from adult rodents and primates adopt photoreceptor-specific phenotypes. Invest Ophthalmol Vis Sci 46:3411-3419.

Bedard A, Parent A. 2004. Evidence of newly generated neurons in the human olfactory bulb. Brain Res Dev Brain Res 151:159-168.

Branchek T, Bremiller R. 1984. The development of photoreceptors in the zebrafish, Brachydanio rerio. I. Structure. J Comp Neurol 224:107115.

Cai L, Morrow E, Cepko CL. 2000. Misexpression of basic helix-loop-helix genes in the murine cerebral cortex affects cell fate choices and neuronal survival. Development 127:3021-3030.
Chae JH, Stein GH, Lee JE. 2004. NeuroD: the predicted and the surprising. Mol Cells 18:271-288.

Cho JH, Kwon IS, Kim S, Ghil SH, Tsai MJ, Kim YS, Lee YD, Suh-Kim H. 2001. Overexpression of BETA2/NeuroD induces neurite outgrowth in F11 neuroblastoma cells. J Neurochem 77:103-109.

Farah MH, Olson JM, Sucuc HB, Hume RI, Tapscott SJ, Turner DL. 2000. Generation of neurons by transient expression of neural bHLH proteins in mammalian cells. Development 127:693-702.

Fischer AJ, Wang S-Z, Reh TA. 2004. NeuroD induces the expression of visinin and calretinin by proliferating cells derived from toxindamaged chicken retina. Dev Dyn 229:555-563.

Hatakeyama J, Tomita K, Inoue T, Kageyama R. 2001. Roles of homeobox and bHLH genes in specification of a retinal cell type. Development 128:1313-1322.

Hevner RF, Hodge RD, Daza RA, Englund C. 2006. Transcription factors in glutamatergic neurogenesis: conserved programs in neocortex, cerebellum, and adult hippocampus. Neurosci Res 55:223-233.

Hitchcock PF, Kakuk-Atkins L. 2004. The basic helix-loop-helix transcription factor neuroD is expressed in the rod lineage of the teleost retina. J Comp Neurol 477:108-117.

Hitchcock PF, Raymond PA. 2004. The teleost retina as a model for developmental and regeneration biology. Zebrafish 1:257-271.

Hitchcock PF, Macdonald RE, VanDeRyt JT, Wilson SW. 1996. Antibodies against Pax6 immunostain amacrine and ganglion cells and neuronal progenitors, but not rod precursors, in the normal and regenerating retina of the goldfish. J Neurobiol 29:399-413.

Hitchcock PF, Otteson DC, Cirenza PF. 2001. Expression of the insulin receptor in the retina of the goldfish. Invest Ophthalmol Vis Sci 42: 2125-2129.

Hu M, Easter SS. 1999. Retinal neurogenesis: the formation of the initial central patch of postmitotic cells. Dev Biol 207:309-321.

Inoue T, Hojo M, Bessho Y, Tano Y, Lee JE, Kageyama R. 2002. Math3 and NeuroD regulate amacrine cell fate specification in the retina. Development 129:831-842.

Johns PR. 1982. Formation of photoreceptors in larval and adult goldfish. J Neurosci 2:178-198.

Julian D, Ennis K, Korenbrot JI. 1998. Birth and fate of proliferative cells in the inner nuclear layer of the mature fish retina. J Comp Neurol 394:271-282

Kay JN, Finger-Baier KC, Roeser T, Staub W, Baier H. 2001. Retinal ganglion cell genesis requires lakritz, a zebrafish atonal homolog. Neuron 30:725-736.

Kim WY, Fritzsch B, Serls A, Bakel LA, Huang EJ, Reichardt LF, Barth DS, Lee JE. 2001. NeuroD-null mice are deaf due to a severe loss of the inner ear sensory neurons during development. Development 128:417426.

Korzh V, Sleptsova I, Liao J, He J, Gong Z. 1998. Expression of zebrafish bHLH genes ngn1 and nrd defines distinct stages of neural differentiation. Dev Dyn 213:92-104.

Larison KD, Bremiller R. 1990. Early onset of phenotype and cell patterning in the embryonic zebrafish retina. Development 109:567-576.

Lawoko-Kerali G, Rivolta MN, Lawlor P, Cacciabue-Rivolta DI, LangtonHewer C, vanDoominck JH, Holley MC. 2004. GATA3 and NeuroD distinguish auditory and vestibular neurons during development of the mammalian inner ear. Mech Dev 121:287-299.

Lee JE, Hollenberg SM, Snider L, Turner DL, Lipnick N, Weintraub H. 1995. Conversion of Xenopus ectoderm into neurons by NeuroD, a basic helix-loop-helix protein. Science 268:836-844.

Lee JK, Cho JH, Hwang WS, Lee YD, Reu DS, Suh-Kim H. 2000. Expression of neuroD/BETA2 in mitotic and postmitotic neuronal cells during the development of nervous system. Dev Dyn 217:361-367.

Li Z, Hu M, Ochocinska MJ, Joseph NM, Easter SS Jr. 2000. Modulation of cell proliferation in the embryonic retina of zebrafish (Danio rerio). Dev Dyn 219:391-401.

Liu M, Pereira FA, Price SD, Chu MJ, Shope C, Himes D, Eatock RA, Brownell WE, Lysakowski A, Tsai MJ. 2000a. Essential role of BETA2/ NeuroD1 in development of the vestibular and auditory systems. Genes Dev 14:2839-2854.

Liu M, Pleasure SJ, Collins AE, Noebels JL, Naya FJ, Tsai MJ, Lowenstein DH. 2000b. Loss of BETA2/NeuroD leads to malformation of the dentate gyrus and epilepsy. Proc Natl Acad Sci U S A 97:865-870.

Manglapus GL, Youngentob SL, Schwob JE. 2004. Expression patterns of basic helix-loop-helix transcription factors define subsets of olfactory progenitor cells. J Comp Neurol 479:216-233. 
Masai I, Stemple DL, Okamoto H, Wilson SW. 2000. Midline signals regulate retinal neurogenesis in zebrafish. Neuron 27:251-263.

Mears AJ, Kondo M, Swain PK, Takada Y, Bush RA, Saunders TL, Sieving PA, Swaroop A. 2001. Nrl is required for rod photoreceptor development. Nat Genet 29:447-452.

Miyata T, Maeda T, Lee JE. 1999. NeuroD is required for differentiation of the granule cells in the cerebellum and hippocampus. Genes Dev 13: 1647-1652.

Moore KB, Schneider ML, Vetter ML. 2002. Posttranslational mechanisms control the timing of bHLH function and regulate retinal cell fate. Neuron 34:183-195.

Morrow EM, Furukawa T, Lee JE, Cepko CL. 1999. NeuroD regulates multiple functions in the developing neural retina in rodent. Development 126:23-36.

Mueller T, Wullimann MF. 2002. Expression domains of neuroD ( $\mathrm{rrd}$ ) in the early postembryonic zebrafish brain. Brain Res Bull 57:377-379.

Mutoh H, Fung BP, Naya FJ, Tsai MJ, Nishitani J, Leiter AB. 1998. The basic helix-loop-helix transcription factor BETA2/NeuroD is expressed in mammalian enteroendocrine cells and activates secretin gene expression. Proc Natl Acad Sci U S A 94:3560-3564.

Naya FJ, Huang HP, Qiu Y, Mutoh H, DeMayo FJ, Leiter AB, Tsai MJ. 1997. Diabetes, defective pancreatic morphogenesis, and abnormal enteroendocrine differentiation in BETA2/neuroD-deficient mice. Genes Dev 11:2323-2334.

Nibu K, Kondo K, Ohta Y, Ishibashi T, Rothstein JL, Kaga K. 2001. Expression of NeuroD and TrkB in developing and aged mouse olfactory epithelium. Neuroreport 12:1615-1619.

Otteson DC, Hitchcock PF. 2003. Stem cells in the teleost retina: persistent neurogenesis and injury-induced regeneration. Vis Res. 43:927-936.

Otteson DC, D'Costa AR, Hitchcock PF. 2001. Putative stem cells and the lineage of rod photoreceptors in the mature retina of the goldfish. Dev Biol 232:62-76.

Pennesi ME, Cho JH, Yang Z, Wu SH, Zhang J, Wu SM, Tsai MJ. 2003. BETA2/NeuroD1 null mice: a new model for transcription factordependent photoreceptor degeneration. J Neurosci 23:453-461.

Pleasure SJ, Collins AE, Lowenstein DH. 2000. Unique expression patterns of cell fate molecules delineate sequential stages of dentate gyrus development. J Neurosci 20:6095-6105.
Raymond PA, Barthel LK. 2004. A moving wave patterns the cone photoreceptor mosaic array in the zebrafish retina [review]. Int J Dev Biol 48:935-945.

Raymond PA, Rivlin PK. 1987. Germinal cells in the goldfish retina that produce rod photoreceptors. Dev Biol 122:120-138.

Raymond PA, Barthel LK, Curran GA. 1995. Developmental patterning of rod and cone photoreceptors in embryonic zebrafish. J Comp Neurol 359:537-550.

Schmitt EA, Dowling JE. 1996. Comparison of topographical patterns of ganglion and photoreceptor cell differentiation in the retina of the zebrafish, Danio rerio. J Comp Neurol 371:222-234.

Schmitt EA, Dowling JE. 1999. Early retinal development in the zebrafish, Danio rerio: light and electron microscopic analyses. J Comp Neurol 404:515-536.

Schonhoff SE, Giel-Moloney M, Leiter AB. 2004. Minireview: development and differentiation of gut endocrine cells [review]. Endocrinology 145: $2639-2644$.

Schwab MH, Bartholomae A, Heimrich B, Feldmeyer D, Druffel-Augustin S, Goebbels S, Naya FJ, Zhao S, Frotscher M, Tsai MJ, Nave KA. 2000. Neuronal basic helix-loop-helix proteins (NEX and BETA2/NeuroD) regulate terminal granule cell differentiation in the hippocampus. J Neurosci 20:3714-3724.

Shen YC, Raymond PA. 2004. Zebrafish cone-rod (crx) homeobox gene promotes retinogenesis. Dev Biol 269:237-251.

Stenkamp DL, Barthel LK, Raymond PA. 1997. Spatiotemporal coordination of rod and cone photoreceptor differentiation in goldfish retina. J Comp Neurol 382:272-284.

Westerfield M. 2000. The zebrafish book: a guide for the laboratory use of zebrafish (Brachydanio rerio). Eugene, OR: Institute of Neuroscience, University of Oregon.

Yan RT, Wang SZ. 1998. NeuroD induces photoreceptor cell overproduction in vivo and de novo generation in vitro. J Neurobiol 36:485-496.

Yan RT, Wang SZ. 2000. Expression of an array of photoreceptor genes in chick embryonic retinal pigment epithelium cultures under the induction of neuroD. Neurosci Lett 280:83-86.

Yan RT, Wang SZ. 2004. Requirement of neuroD for photoreceptor formation in the chick retina. Invest Ophthalmol Vis Sci 45:48-58. 